\author{
Cadernos de \\ ESTUDOS LINGǘlSTICOS - (54.1), Campinas, Jan./Jun. 2012
}

\title{
A ESTRUTURA PROSÓDICA DAS DISFLUÊNCIAS EM PORTUGUÊS BRASILEIRO $^{1}$
}

\author{
ESTER SCARPA ${ }^{2}$ \\ FLAVIANE FERNANDES-SVARTSMAN ${ }^{3}$
}

\begin{abstract}
RESUMO
Este artigo trata de buscar as tendências de ocorrência de disfluências (repetições hesitativas e alongamentos vocálicos não-enfáticos) no interior dos domínios prosódicos do enunciado. Usando modelos de Fonologias Prosódica e Entoacional, aplicado a um corpus de um trecho de fala espontânea, verifica-se: (i) que as repetições e alongamentos hesitativos se dão com maior frequência com clíticos prosódicos; (ii) que repetições hesitativas não envolve cabeça de frase fonológica de frase entoacional e, se a repetição hesitativa envolve a palavra fonológica, esta é sempre não cabeça de frase fonológica ou frase entoacional; (iii) que há abaixamento de tessitura do contorno entoacional dos trechos com repetições hesitativas, fenômeno já notado por Viscardi (2012); e (iv) que depois das repetições hesitativas, é grande a incidência de atribuição de configuração tonal de foco encontrada em português brasileiro ( $\mathrm{H}^{*}+\mathrm{L}$ ou L*+H L-). Trechos hesitativos, considerados na literatura como marcas de "disfluência", fazem parte da dinâmica da fala e da elaboração do texto oral. Se, por um lado, sua ocorrência é imprevisível no discurso (embora cíclica), quando ocorrem, não são aleatórios prosodicamente.
\end{abstract}

Palavras-Chave: Disfluências, análise prosódica, fala espontânea

\begin{abstract}
The aim of this article is to look at the tendencies of occurrence of disfluency (hesitating repetitions and non-emphatic vowel lengthening) within prosodic domains. Data from spontaneous speech were analyzed using principles of Prosodic and Intonational Phonology. The main conclusions are: (i) hesitating repetitions and lengthnenings are more frequent with prosodic clitics; (ii) hesitating repetitions involve neither the head of phonological phrase nor the head of the intonational phrase; (iii) if the repetition involves the phonological word, this is not the head of a phonological or intonational phrase; and (iv) there is lowering of pitch range of the repetition stretches, as Viscardi (2012) has already noticed; ( $v$ ) after hesitating repetitions, there is a strong possibility of occurrence of assignment of (Brazilian Portuguese) focus configuration $\left(H^{*}+\mathrm{L}\right.$ or $\left.\mathrm{L}^{*+\mathrm{H}} \mathrm{L}-\right)$. Seen as "disfluency" by the literature, hesitation stretches of the utterance are part of the dynamics of speech and elaboration of the oral text. They are unpredictable in the discourse, albeit cyclical. When they do occur, however, they are not prosodically random.
\end{abstract}

Keywords: Disfluency, prosodic analysis, spontaneous speech.

1. Agradecemos ao apoio, no desenvolvimento deste trabalho, dos seguintes órgãos de fomento à pesquisa: $\mathrm{CNPq}$ (Bolsa de Produtividade em Pesquisa processo no. 301895/2010-4), para a primeira autora, e FAPESP (processo 2011/50044-9), FCT (PTDC/CLE-LIN/119787/2010), para a segunda autora.

2. UNICAMP/IEL. Campinas (SP), Brasil. e-mail: scarpa@iel.unicamp.br

${ }^{3 .}$ USP. São Paulo (SP), Brasil. e-mail: flaviane@usp.br 


\section{INTRODUÇÃO}

Em Scarpa (1995; artigo revisado e modificado em 2006), são exploradas questões sobre as dificuldades da conceituação de fluência (e sua contraparte, a disfluência). Na literatura linguística, até recentemente, o conceito de "fluência" vinha na negativa: a fala fluente seria aquela "destituída de disfluências" (Hedge, 1978, apud Finn \& Ingham, 1991). Além disso, o campo privilegiado do estudo da fluência/ disfluência era exatamente o dos distúrbios de fala e linguagem, pois lidava-se com disfluências que envolveriam sua contraparte patológica (a gagueira, por exemplo) A disfluência tem sido considerada o termo marcado, desviante, vinculada a outro termo marcado: problemas de elaboração ou processamento (planejamento), normalmente de memória, de acesso lexical, isto é, dificuldade linguística ou psicolinguística. "Fluência" tem sido tradicionalmente vista como o termo não marcado e considerado ideal, ao passo que "disfluência" tem sido considerado como o problemático.

Mais recentemente, porém, no bojo de correntes que enfatizam o estudo da fala, o conceito de fluência, a explicitação e as condições de distribuição entre fluência e disfluência têm despertado mais interesse aos linguistas. O propósito tem igualmente sido o de buscar uma definição positiva do que é fala fluente e não apenas considerá-la default e neutra para a montagem de corpora objetivados ao escrutínio científico.

O desafio é, então, abordar os dois conceitos, em princípios opostos e conflitantes, como faces da mesma moeda.

Entre os foneticistas, já há um bom tempo (ver Scarpa, 1995; 2006) que a referência aos processos constitutivos da dinâmica da fala fá-los tratar a fluência e disfluência de modo integrado. O argumento fonético se organiza segundo princípios desenvolvidos em Lindblom (1990). Os gestos fonéticos são adaptativos e maleáveis às demandas de mudanças de estilo de fala de rápido para vagaroso, baixo para alto, informal para claro, bem articulado, íntimo para público. Falamos de modo diferente quando nos dirigimos a estrangeiros, bebês, computadores e pessoas com problemas de audição. Modulamos nossa fala, mesmo involuntariamente, em resposta a fatores fisiológicos e emocionais. A variação fonética abunda se comparamos amostras de fala de um mesmo indivíduo ou vários falantes. Por outro lado, a fala é adaptativa. Sub-utiliza os assim chamados "graus de liberdade" disponíveis em princípio. Não lança mão de recursos mais potentes nem maiores do que o necessário. Não é mais elaborada do que precisa ser. A fala, comparada com outras atividades, é, segundo Lindblom, um "pianissimo fisiológico", o que aponta para o fato de que aparentemente severas restrições governam a seleção de valores linguístico-fonéticos. De acordo com o autor, estas restrições não repousam na invariância do sinal. Esta não é nem necessária, nem suficiente para o acesso lexical, uma vez que a estrutura das línguas exibe redundâncias. Além disso, a percepção da fala é um produto de dois tipos de informação: a voltada ao sinal e a independente do sinal; neste último caso, a informação relevante é de natureza sobretudo linguística. Deslocando o perceptual para a língua, Lindblom hipotetiza que tais restrições têm a ver com 
o princípio de contraste perceptual suficiente que, por sua vez, encontra-se em tensão com o princípio da simplificação articulatória, que diz, resumidamente, o seguinte: os gestos fonéticos não são feitos mais distintivos do que precisam ser; a fala evita gestos articulatoriamente extremos (por exemplo, pode-se pronunciar um [i] com a mandíbula abaixada, mas este é um esforço inútil, portanto descartável). A tensão entre estas duas restrições - ou, em termos mais econômicos, entre simplicidade e complexidade articulatória - estão na gênese dos processos fundamentais de dinâmica da fala. Tal tensão (ou "equilíbrio") indica que, quando demandas por contrastes perceptuais diminuem, o gesto se simplifica, cedendo lugar à disfluência.

Pesquisadores brasileiros, em trabalhos experimentais, chegam a conclusão semelhante: traços de disfluência são constitutivos da dinâmica da fala. Merlo (2006), por exemplo, descreve foneticamente as hesitações na fala semi-espontânea através da análise por séries temporais. Conclui que a organização das disfluências é periódica e, portanto, a hesitação não é um fenômeno aleatório temporalmente, porque suas oscilações se repetem ao longo do tempo. Para além de negar o caráter marginal, supérfluo, degenerado e aleatório das pausas e hesitações, Merlo (2012) vai adiante: afirma sua necessidade para a própria fluência da fala, uma vez que sinalizam decisões do falante sobre o planejamento conceitual e a formulação linguística do texto oral.

A pausa, aliás, tem sido estudada há mais tempo. Por ser um elemento prosódico, pelo valor tanto textual, de processamento da informação, como potencialmente sintático, tem merecido a atenção dos investigadores. Vista como uma das marcas formais de planejamento e processamento linguistico (ScliarCabral, Martim \& Chiari, 1981), a tendência de ocorrência de pausas tem sido relacionada a fatores lexicais e sintáticos. Segundo Cruttenden (1997), e retomando Scarpa (2006), as pausas ocorreriam tipicamente em três lugares do enunciado:

(i) em fronteiras de constituintes maiores, principalmente entre orações e entre sujeito e predicado. Há uma correlação entre o tipo de fronteira de constituinte e a duração da pausa - quanto maior (mais superordenada) a fronteira, mais longa será a pausa. As pausas tendem a ser mais longas nos pontos em que as fronteiras de constituintes envolvem um novo tópico.

(ii) antes de palavras de alto conteúdo lexical (isto é, "pontos de probabilidade transicional baixa"). Este tipo de pausa tipicamente ocorre antes de uma fronteira menor (mais encaixada) de constituinte (por exemplo, entre um determinante e a cabeça do sintagma seguinte). Indica, geralmente, "dificuldade de encontrar a palavra". Pode ser preenchida ou não.

(iii) depois da primeira palavra de um grupo entonacional (posição típica de outros 'erros de performance'), como por exemplo, correções de falsos começos e repetições.

As pausas do tipo (ii) e (iii) devem ser geralmente tomadas como "fenômenos de hesitação". Já as do tipo (i) são as chamadas pausas de respiração, que não indicam disfluência. 
Trabalhos sobre o português oral, especialmente pesquisas sobre as características de composição (ou elaboração) e planejamento do texto oral, também tratam da questão da disfluência (Koch \& Silva, 1996; Marcuschi, 1999). Partindo do princípio de que, na linguagem oral, um texto consiste, pelo menos em parte, na própria produção do texto, fenômenos típicos de interrupções, reinícios, correções, paráfrases, repetições, hesitações apresentam-no em constante statu nascendi. No plano formal (fônico), disfluências 'on line' acontecem pari passu com a hierarquização discursiva: hesitações, pausas (preenchidas ou não), interrupções do fluxo de fala, cortes oracionais, repetições de sílaba, falsos começos. No plano informacional (do conteúdo), caracterizam-se por desvios da linearidade do fluxo informacional: paráfrases, repetições, retomadas, autocorreções, digressões tópicas, inserções.

Estes dois tipos de "disfluências" interagem. Por exemplo, em formulações altamente fluentes do ponto de vista formal, encontram-se paráfrases e repetições (auto-repetições, no caso de uma elocução formal) que não visam absolutamente a corrigir "problemas" de formulação, mas, pelo contrário, desempenham funções importantes - retóricas, argumentativas, didáticas. Também em textos falados que são diálogos, o desenvolvimento do tópico é todo permeado de retomadas, digressões, repetições do discurso do interlocutor ou de sua própria fala.

Em vista de tais evidências, Scarpa $(1995 ; 2006)$ conclui que

\begin{abstract}
a fluência é uma abstração metodológica, baseada na leitura ensaiada ou "profissional" de um texto escrito ou em textos orais decorados e ensaiados. O sujeito fluente é abstrato e integra-se em algum estilo de fala ou de comportamento social. No entanto, é com esta abstração ou esta ilusão - necessária, em termos de recorte epistemológico- que se têm constituído os corpora analisados por modelos linguísticos (Scarpa, 2006, p. 174).
\end{abstract}

Hesitações, interrupções da cadeia de fala, inserções ou reduções de fragmentos, retomadas, repetições, falsos começos, reelaborações, que configuram basicamente uma fala disfluente, foram tratados, na literatura, como "atividades epilinguísticas": as que o sujeito faz com a linguagem, atuando consigo mesmo ou através da intermediação do outro, de discursos anteriores, da própria forma linguística (Scarpa, 1987). Estas atividades ou operações se oporiam às metalinguísticas (que se vinculam à construção, pela linguagem, de um sistema representativo-nocional que descrevem os fenômenos linguísticos observados pelo sujeito, colocando o sujeito fora da linguagem e trazendo a construção desse sistema por ela própria) e as linguísticas, atividades comunicativas e representativas do sujeito na linguagem. Entretanto, esta divisão tripartite acaba sendo também teoricamente custosa, uma vez que envolve concepções diversificadas e ambíguas de sujeito e sua relação com a linguagem, além de, como vimos, fazerem parte da dinâmica da fala. Preferimos, aqui, considerá-las todas como atividades da língua, como uma maneira mais integrada de dar conta da fluência/disfluência. Nossa visão é que as fluências e as disfluências distribuem-se na língua segundo pressões semânticas, pragmáticas, comunicativas e prosódicas. As disfluências tendem a ocorrer em certos pontos do enunciado prosódico e não são aleatoriamente distribuídas por qualquer parte dos domínios prosódicos. 
Observações preliminares com dados infantis, (cf. Scarpa, 1995; 2006) que envolvem, grosso modo, um período recorrente de disfluência infantil, abrangendo a faixa etária aproximada de 2 a 4 anos de idade, também chamado de "gagueira fisiológica", aponta para uma tendência a maior fluência em certos trechos nucleares da unidade entoacional ${ }^{4}$ envolvida, ao passo que as disfluências, a não ser as pausas fluentes, tendem a aparecer no começo da unidade entoacional e não no fim dela. Tais trechos, em seu termo neutro ou default, são reservados às sílabas portadoras de proeminência prosódica. Prosodicamente, a disfluência não ocorreria nos trechos nucleares, mas nos periféricos e fronteiriços, anteriores ao núcleo, isto é, nos pés fracos, antes da cabeça de constituintes prosódicos.

Apenas recentemente é que alguns trabalhos têm focalizado a disfluência (e a sua face dita "desviante", a gagueira) e a têm estudado sob o prisma de teorias fonológicas prosódicas e entoacionais, que têm contribuído para esclarecer algumas facetas dos loci prosódicos das disfluências de gagos e de não-gagos. Os resultados a que Cruz (2009) tem chegado, como veremos abaixo, podem ser úteis para o propósito de nossos objetivos, a saber, melhor determinar a estrutura prosódica da fluência/ disfluência.

É objetivo deste artigo, então, traçar as tendências de ocorrência de disfluências (repetições hesitativas e alongamentos vocálicos não-enfáticos) no interior dos domínios prosódicos do enunciado, à luz da Fonologia Prosódica e da Fonologia Entacional, como veremos a seguir.

\section{QUADRO TEÓRICO.}

Do ponto de vista prosódico, analisaremos os $\operatorname{dados}^{5}$ (ver abaixo sua especificação) deste trabalho à luz da Fonologia Entoacional (cf. Pierrehumbert, 1980; Beckman \& Pierrehumbert, 1986; Pierrehumbert \& Beckman, 1988; Hayes \& Lahiri, 1991; Ladd, 1996, 2008; Jun, 2005; entre outros), no que se refere à análise entoacional, e da Fonologia Prosódica (cf. Selkirk, 1984, 1986, 2000; Nespor \& Vogel, 1986; entre outros), no que se refere à formação de domínios prosódicos.

A adoção dessas duas teorias fonológicas de análise prosódica se justifica na medida em que assumimos aqui uma visão integrada de entoação e organização dos domínios prosódicos (cf. Hayes \& Lahiri, 1991; Frota, 2000; Tenani, 2002). Conforme tal visão, há correspondência entre os domínios delimitados entoacionalmente e os derivados de algoritmos da Fonologia Prosódica.

Passemos à descrição sucinta dos pressupostos teóricos das duas teorias de análise prosódica referidas.

4. A essa unidade entoacional chamaremos de "frase fonológica" ou "frase entoacional", segundo o modelo adotado aqui. Ver adiante.

5. Os dados serão detalhados na sessão 3 deste artigo. 


\subsection{Fonologia Entoacional}

A Fonologia Entoacional consiste em uma abordagem da estrutura entoacional que pressupõe que a entoação tem uma organização fonológica (cf. Beckman \& Pierrehumbert, 1986; Pierrehumbert \& Beckman, 1988; Hayes \& Lahiri, 1991; Ladd, 1996, 2008; Jun, 2005; entre outros). Um de seus principais objetivos é tentar fornecer um aparato descritivo potencialmente universal para a entoação.

Conforme a ótica da Fonologia Entoacional, um contorno entoacional consiste, fonologicamente, em uma sequência de unidades discretas, os eventos tonais. Esses eventos tonais são localmente definidos, constituem blocos de contorno e estão associados a pontos específicos na cadeia segmental. A representação fonética de uma sequência de eventos tonais consiste no contorno da frequência fundamental $\left(\mathrm{F}_{0}\right)$.

Em línguas como o inglês e o português, por exemplo, os eventos tonais mais importantes da cadeia tonal são os acentos tonais e os tons relacionados a fronteiras. Os acentos tonais são associados a sílabas proeminentes na cadeia segmental e podem ser simples, monotonais $\left(\mathrm{L}^{*}\right.$ ou $\left.\mathrm{H}^{*}\right)$, ou complexos, bitonais $\left(\mathrm{H}^{*}+\mathrm{L}, \mathrm{H}+\mathrm{L}^{*}\right.$, $\mathrm{L}^{*}+\mathrm{H}$ ou $\left.\mathrm{L}+\mathrm{H}^{*}\right)$. Os tons relacionados a fronteiras são associados a fronteiras de domínios prosódicos e podem ser de dois tipos: tons de fronteira (boundary tones: $\mathrm{L} \%$ ou $\mathrm{H} \%$ ) ou acentos frasais (phrasal accents: $\mathrm{L}^{-}$ou $\mathrm{H}^{-}$), conforme a notação de Pierrehumbert. ${ }^{6} \mathrm{Na}$ análise entoacional dos dados deste trabalho, tomaremos como base trabalhos sobre a entoação do português brasileiro, já desenvolvidos no quadro teórico da Fonologia Entoacional (cf. Frota \& Vigário, 2000; Tenani, 2002; Fernandes, 2007; Serra, 2009; Vigário \& Fernandes-Svartman, 2010; entre outros).

\subsection{Fonologia Prosódica}

A Fonologia Prosódica é uma teoria da estrutura fonológica e sua relação com a sintaxe (cf., entre outros, Selkirk, 1984, 1986, 2000; Nespor \& Vogel, 1986).

Segundo essa teoria, o fluxo da fala é organizado hierarquicamente dentro de domínios prosódicos e a evidência para esta hierarquia prosódica provém da operação de regras fonológicas, que se aplicam no interior e entre junturas de certos domínios e que são bloqueadas no interior e entre junturas de outros.

A estrutura prosódica é parcialmente determinada pela estrutura sintática. Em alguns casos, essas duas estruturas podem coincidir, e, em outros, divergir. Esta é a razão por que a sintaxe nem sempre faz as previsões corretas sobre a estrutura prosódica.

6. Na literatura linguística brasileira sobre entoação do PB, "acento frasal" é o termo mais utilizado para a tradução de phrasal accent. 
A relação entre a estrutura sintática e a prosódica é definida por um mapeamento sintático-fonológico que fornece uma representação prosódica consistindo em uma hierarquia de constituintes prosódicos.

Tal hierarquia, na perspectiva de Nespor \& Vogel (1986), por exemplo, é disposta como indicado em (1), incluindo desde a sílaba até o enunciado:

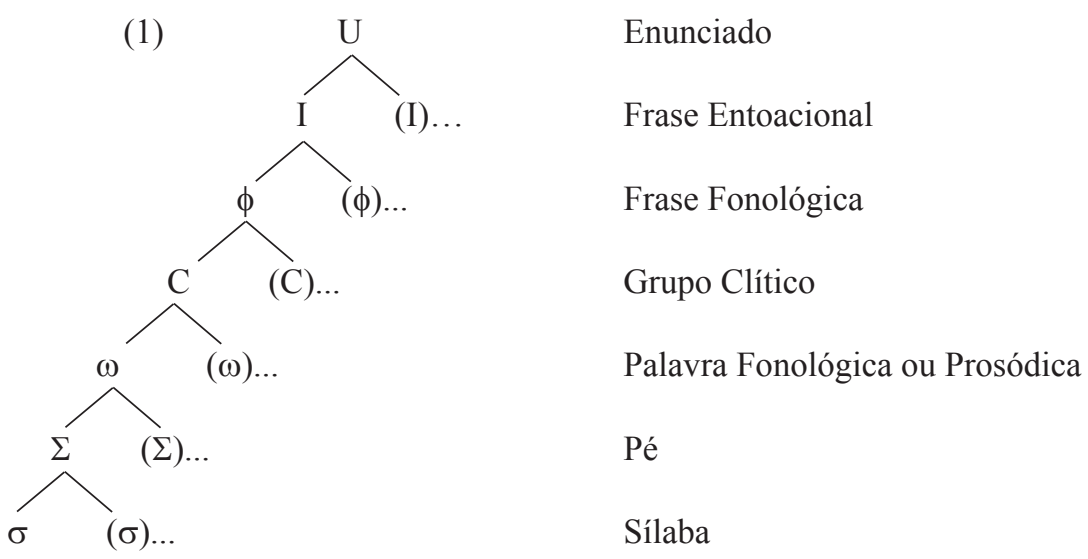

Os níveis prosódicos contemplados em nossa análise são: a palavra fonológica $(\omega)$, a frase fonológica $(\phi)$ e a frase entoacional (I). ${ }^{7} \mathrm{O}$ motivo que nos leva a essa escolha é o fato de que, em PB, o domínio prosódico privilegiado na associação de acentos tonais ao contorno é a frase fonológica (cf. Frota \& Vigário, 2000; Tenani, 2002) e a palavra fonológica (cf. Fernandes, 2007a, b; Tenani \& Fernandes-Svartman, 2008) e os domínios privilegiados na associação de acentos frasais e tons de fronteira são, respectivamente, a frase fonológica (cf. Fernandes, 2007a, b; Tenani \& Fernandes-Svartman, 2008) e a frase entoacional (cf. Frota \& Vigário, 2000; Tenani, 2002; Fernandes, 2007a, b; Serra, 2009).

\subsection{Reflexões sobre disfluência à luz de uma visão integrada entre Fonologia Prosódica e Fonologia Entoacional.}

O trabalho pioneiro de Cruz (2009) investiga dados de sujeitos gagos (estes julgados como portadores de gagueira severa) e não-gagos, falantes do português

7. Em linhas gerais, a palavra fonológica $(\omega)$ é o domínio prosódico no qual pode haver apenas um acento primário (ou lexical); o sintagma fonológico $(\phi)$ corresponde ao domínio de uma categoria sintática máxima (XP) nas teorias end-based (cf. Selkirk, 1986; 2000; entre outros) e, nas teorias relation-based de Fonologia Prosódica (cf. Nespor \& Vogel, 1986), ao domínio que abrange, inicialmente, um núcleo lexical e todos os elementos funcionais do lado oposto à recursividade sintática até o próximo núcleo lexical; e o sintagma entoacional (I) consiste no domínio do contorno de $\mathrm{F}_{0}$ delimitado por pausas ou pela mudança da gama de variação de $\mathrm{F}_{0}$ em dado trecho do contorno, com posterior estabilização da gama de variação inicial. 
europeu, para determinar a caracterização prosódica do discurso disfluente, os loci prosódicos da disfluência (sem fazer distinção dos dados entre gagos e não-gagos) e a relevância de fatores prosódicos para a ocorrência de gagueira. Baseia-se nas teorias de fonologia prosódica e leva em conta os domínios prosódicos considerados relevantes para o português (Frota, 2009; Vigário, entre outros): grupo clítico (CL), palavra prosódica (PW), sintagma fonológico (frase fonológica, na literatura prosódica brasileira - $\mathrm{PhP}$ ), sintagma entoacional (frase entoacional, na literatura prosódica brasileira - I), com intermediate phrases $(\mathrm{Ip})^{8}$ consideradas relevantes, para o estudo da disfluência ${ }^{9}$, entre os dois últimos domínios. Leva também em conta as relações dos domínios prosódicos com o fraseamento entoacional do português, com os padrões de distribuição dos acentos tonais, com base na Teoria Fonologia Entoacional (Ladd, 1996, 2008; Beckman \& Pierrehumbert, 1986).

Cruz (op. cit.), analisando dados semi-espontâneos e lidos, colhidos num desenho experimental com dados equilibrados prosodicamente, conclui que a disfluência gaga revela uma maior densidade de acentos tonais por I, Is mais curtos, produção de maior quantidade de bloqueios, repetições, pausas preenchidas. Além disso, os eventos disfluentes, para ambos os grupos, tendem a ocorrer no que chama de $\mathrm{PhP}$ : posição inicial prosódica, desencadeada e antecipada pelo acento tonal da primeira palavra prosódica do I. Seu trabalho alia a pesquisa experimental, a descrição e medidas estatísticas a indagações importantes sobre os fatores estruturais (fonéticos e fonológico-prosódicos) da disfluência. Aponta para a relevância de modelos prosódicos para a consideração dos dados disfluentes.

\section{DESCRIÇÃo E METODOLOGIA DE ANÁLISE DOS DADOS}

Metodologicamente, é compreensível a eleição de dados de leitura para a viabilidade de descrições linguísticas finas. Adiantamos, , porém, que consideramos os dados lidos como um dos possíveis estilos de fala, assim como a conversação livre, e não como o estilo default, cuja elicitação tem sido largamente eleita como constituidora de amostragens de dados preferenciais, seguros e neutros para descrição linguística. O desafio metodológico deste trabalho é, então, trabalhar com hipóteses e quadro descritivo de Fonologias Prosódica e Entoacional para dados de fala espontânea, sem negar, obviamente, o valor do recorte metodológico, para casos específicos, de se trabalhar com o que na literatura se chama de "dado neutro", isto é, lido e homogeneizado, ou "semi-espontâneo", isto é, a narrativa da fala do informante a partir de tiras desenhadas.

8. Intermediate phrase é um constituinte relevante para a descrição entoacional de certas línguas, como o francês, por exemplo, porém, é um constituinte não coincidente necessariamente com os constituintes previstos pela Fonologia Prosódica (cf. Selkirk, 1984, 1986; Nespor \& Vogel, 1986). Grosso modo, tal constituinte corresponde a um constituinte intermediário entre a frase fonológica e a frase entoacional da Fonologia Prosódica.

9. Os gagos, por exemplos, realizariam intermediate phrases leves e pequenas quando comparados aos não-gagos. 
Os dados aqui analisados correspondem a momentos de hesitação extraídos da produção de um trecho digitalizado de um texto monológico, depoimento e/ou entrevista de um sujeito (Chico Buarque de Holanda (CBH), DVD "Uma palavra", RWR Comunicações). No texto, $\mathrm{CBH}$ dá conta do seu processo criativo como compositor $^{10}$. O trecho completo segue abaixo:

Bom, isso acontece com tudo, acontece coa coa coas palavras da da música, como acontece com a própria com a própria música.psã ps Acontece por exemplo você você ta tocando violão procurando uma alguma coisa ... de repente é... ${ }^{2} a^{2} a$ (falso começo) há quase uma inteligência tátil né na nas mãos aí a a a a mão vai ou você erra, erra o traste $e^{?}$ de repente faz um acorde que não era o que você está procurando e aí você diz: "ô, que interessante esse acorde errado. Em cima do erro, muitas vezes você faz você você cria...músicas. Como pode criar também a:.: letra de música, uma palavra que aparece meio...de forma gratuita, você não esperava, por que que apareceu esta palavra na minha frente, aqui? Ah, já que apareceu vamos / vamos aproveitar.

Isso existe em tudo, né, até na na na na tela do dos pintores, diz-que o Leonardo a: ã da Vinci, ele pintava, ele começava os murais dele, ele começava a pintar aproveitando as manchas ali da na na nos muros, nas paredes, né, aquelas manchas que existe ali já sugeriam ...formas que depois iam se transformar na na na na nas figuras da da da dos dos afrescos dele.

Então é ? a existe, é claro, ${ }^{?} a^{?}$ a coisa do jogo de dados, é da da da ...da ...do imprevisivel...na criação. Por isso que às vezes é tão dificil você falar sobre? $a \ldots{ }^{?} a:^{?} a$ ? $u s^{?}$ o seu trabalho, trabalho literário, o que for, porque muitas vezes você ta inventando em cima disso, o que aconteceu de forma quase inexplicável, né?

Volto a dizer, não é inexplicável tudo, não, você tá trabalhando, tá trabalhando, tá... mas no meio do trabalho aparecem aparecem $m$ coisas, né, aparecem $:$ imagens que você não tava ... não tava buscando. E essas imagens geralmente são bem-vindas, porque são são são ba ba em primeiro momento são erros são são são são ...são ilusões que você depais (sic) pouco cê vai cê vai diz, não, mas pera aí, isso faz, isso faz sentido, isso...Aí cê vai burilando, burilando, burilando.

O texto em questão foi transcrito auditivamente para posterior seleção de eventos disfluentes a serem analisados acusticamente, ocasião em que muitas das transcrições dos trechos disfluentes, feitas preliminarmente de oitiva, foram devidamente corrigidas à luz da evidência espectrográfica. A análise acústica foi feita com a utilização do programa Praat 5.1.31 (Boersma \& Weenink, 2009), em que se especificaram a forma de onda, espectrograma, contorno de $\mathrm{F}_{0}$ e camadas de fraseamento prosódico, com base nos pressupostos teóricos da Fonologia Prosódica (cf. seção 2.2. deste trabalho), e transcrição tonal do trecho, com base nos pressupostos teóricos da Fonologia Entoacional (cf. seção 2.1. deste trabalho).

Os momentos de hesitação correspondem a trechos caracterizados, do ponto de vista prosódico, pela presença de pausas, repetições e alongamentos nãoenfáticos no interior de domínios prosódicos, sendo isso não previsto pela teoria da Fonologia Prosódica ${ }^{11}$. Em tal teoria, pausas e alongamentos não-enfáticos, por

10. O audio foi extraído do DVD com a utilização do programa aberto Audio Extractor, ferramenta livre que permite a extração de faixas de áudio de DVDs, salvando-as em variados arquivos. Escolhemos o arquivo.WAV, bastante usado academicamente para análise de dados de fala.

11. Entendemos aqui por "alongamentos não-enfáticos" os alongamentos de segmentos presentes em sílabas não portadoras de proeminência, portanto, não resultando em um efeito de ênfase na palavra. 
exemplo, podem ser evidências de fronteiras de domínios prosódicos e, portanto, não deveriam ser encontrados no interior desses domínios.

Os trechos selecionados para nossa análise vêm a seguir, com os trechos hesitativos marcados em negrito.

1. acontece coa coa coas palavras da da música.

2. como acontece com a própria com a própria música.

3. psa ps (false start ou pausa preenchida) Acontece por exemplo você você ta tocando violão procurando uma alguma coisa .

4. ' ${ }^{2} \mathbf{a}$ (falso começo) há quase uma inteligência tátil né na nas mãos aí ã Pa a mão vai ou você erra.

5. muitas vezes você faz você você cria...músicas.

6. Como pode criar também a::: letra de música.

7. uma palavra que aparece meio...de forma gratuita.

8. Ah, já que apareceu vamos / vamos aproveitar.

9. Isso existe em tudo, né, até na na na na tela do dos pintores,

10. diz-que o Leonardo ã a da Vinci,

11. ele começava a pintar aproveitando as manchas ali da na na nos muros,

12. que depois iam se transformar na na na na nas figuras da da da dos dos afrescos dele.

13. Então é ${ }^{?}$ a existe, é claro, ${ }^{?} \mathrm{a}^{\mathrm{P}}$ a coisa do jogo de dados, é da da da ...da ...do imprevisível...na criação.

14. Por isso que às vezes é tão difícil você falar sobre ${ }^{2} \mathbf{a} . .^{2} \mathbf{a : ~}^{?} \mathbf{a}^{2} \mathbf{u s}{ }^{2} \mathbf{0}$ seu trabalho,

15. aparecem m coisas, né, aparecem :: imagens que você não tava ... não tava buscando

16. porque são são são ba bə em primeiro momento são erros são são são são ...são ilusões

17. que você depais (sic) pouco cê vai cê vai diz/, não, mas pera aí, isso faz, isso faz sentido, isso.

\section{DISCUSSÃO DOS RESULTADOS}

A análise prosódica dos dados, levando em conta a análise do contorno entoacional associado a eles e a formação de domínios prosódicos, revelam, de um modo geral que:

(i) repetições hesitativas se dão com maior frequência com clíticos prosódicos (itens funcionais desprovidos de acento lexical);

(ii) os alongamentos não-enfáticos hesitativos também se dão com maior frequência em clíticos prosódicos;

(iii) não ocorrem repetições hesitativas envolvendo cabeça de frase fonológica ou cabeça de frase entoacional e, se a repetição hesitativa não envolve o clítico 
prosódico, mas a palavra fonológica, esta é sempre não cabeça de frase fonológica e não cabeça de frase entoacional;

(iv) há abaixamento de tessitura do contorno entoacional dos trechos com repetições hesitativas, fenômeno já notado por Viscardi (2012), com dados espontâneos de fala não-afásica ${ }^{12}$;

(v) depois das repetições hesitativas, é grande a incidência de atribuição de configuração tonal de foco encontrada em português brasileiro $\left(\mathrm{H}^{*}+\mathrm{L}\right.$ ou $\mathrm{L}^{*}+\mathrm{H}$ L-, cf. Fernandes, 2007);

(vi) na repetição hesitativa de clíticos prosódicos não há atribuição de acentos tonais, mas na repetição hesitativa de palavras prosódicas, ainda que não cabeça de frase fonológica, há atribuição de acento tonal; e

(vii) pode haver acento frasal associado à fronteira direita da frase fonológica que antecede o trecho de repetições hesitativas.

A Figura 01 exemplifica as características prosódicas elencadas em (i), (iv), (v), (vi) e (vii).

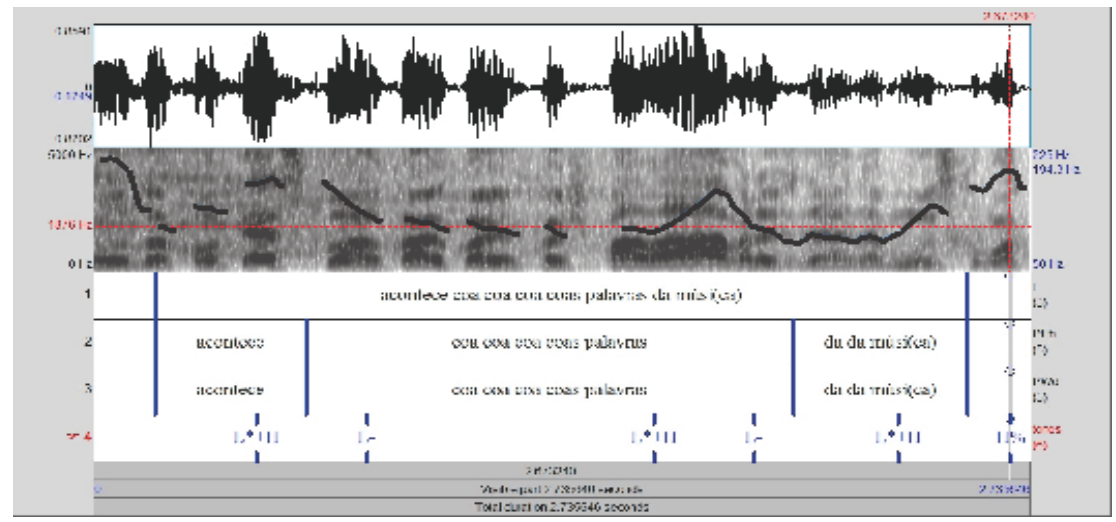

Figura 01. Forma de onda, espectrograma, contorno de $\mathrm{F}_{0}$ e camadas de fraseamento prosódico e transcrição tonal do trecho "acontece coa coa coa coas palavras da da música", produzido por $\mathrm{CBH}$.

Através da observação dessa figura, nota-se que:

a) Há abaixamento da tessitura do contorno entoacional associado a esse trecho de repetição hesitativa.

b) À repetição hesitativa dos clíticos prosódicos "com" e "a", produzidos repetidamente como [kwa] não há atribuição de acentos tonais. Isto é, mesmo que nas repetições $1 \mathrm{e} 2$ de coa... coa..., antes da retomada com "coas palavras" a altura do contorno entoacional permaneça a mesma ou desça um pouco (cf Viscardi, 2012, e neste volume), não é possível atribuir um valor fonológico de tom às primeira e segunda repetições porque, sendo clíticos prosódicos, são desacentuados segundo o modelos de Fonologia Prosódica e Entoacional. Em outras palavras, a esses

12. Ver também artigo de Viscardi, Repetições hesitativas em fala afásica e não-afásica, neste volume. 
clíticos prosódicos está associado um contorno ligeiramente descendente do ponto de vista fonético, mas, a não ser no caso de foco ou ênfase, tais elementos não portam proeminência entoacional do ponto de vista fonológico.

c) Há a ocorrência de acento frasal L- associado à fronteira direita da frase fonológica [(acontece) $\omega] \phi$ que antecede o trecho de repetição hesitativa.

d) Há configuração tonal de foco $\left(\mathrm{L}^{*}+\mathrm{H}\right.$ L-) na palavra fonológica imediatamente seguinte, $([$ palavras $] \omega)$, à repetição hesitativa dos clíticos.

Como dissemos acima, há distribuição entre trechos fluentes e disfluentes no discurso. É possível que o abaixamento de tessitura nos trechos de repetições hesitativas marque relevo negativo no discurso, com o efeito de neutralizar, para o interlocutor, o trecho de hesitação. Por sua vez, é interessante notar que a configuração tonal de focalização, logo após o trecho de repetições hesitativas, marca relevo positivo no discurso, chamando a atenção do interlocutor para esse último trecho (cf. Travaglia, 2006, sobre a marcação de relevo no processamento da informação em português brasileiro).

Passemos agora à Figura 02.

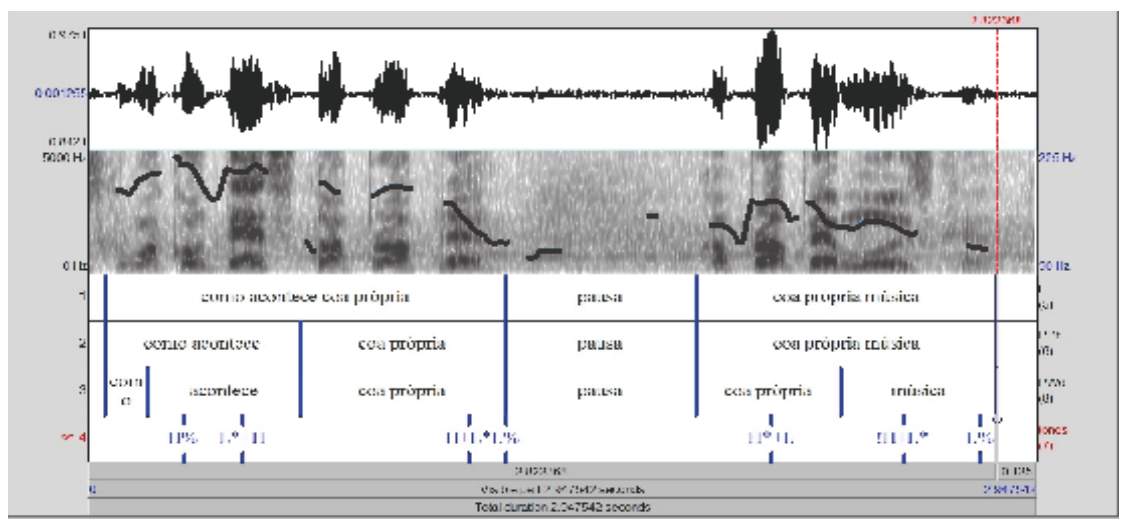

Figura 02. Forma de onda, espectrograma, contorno de $\mathrm{F}_{0}$ e camadas de fraseamento prosódico e transcrição tonal do trecho "como acontece coa própria... coa própria música", produzido por $\mathrm{CBH}$.

No trecho representado pela Figura 02, há repetição hesitativa não apenas de clítico prosódico, mas de uma palavra prosódica inteira (coa própria) $\omega$. Entretanto, constata-se que "coa própria", imediatamente precedida por pausa, não é cabeça de frase fonológica na repetição, mas sim a palavra prosódica "música" é cabeça de frase fonológica, por ser o elemento mais à direita da frase fonológica [(coa própria) $\omega$ (música) $\omega] \phi$. Nesse caso, a repetição hesitativa se dá não com o clítico prosódico, mas com a palavra prosódica não cabeça de frase fonológica e que, por sua vez, recebe acento tonal, enquanto matriz e repetição (respectivamente, acento tonal $\mathrm{H}+\mathrm{L}^{*}$ atribuído à matriz e $\mathrm{H}^{*}+\mathrm{L}$ atribuído à repetição).

Já a Figura 03, abaixo, ilustra o alongamento não-enfático hesitativo do clítico prosódico "a" e abaixamento da tessitura do contorno entoacional associado a esse 
trecho de alongamento hesitativo, seguido por pausa e atribuição de acento tonal marcador de foco, $\mathrm{H}^{*}+\mathrm{L}$, à palavra prosódica subsequente, (letra) $\omega$.

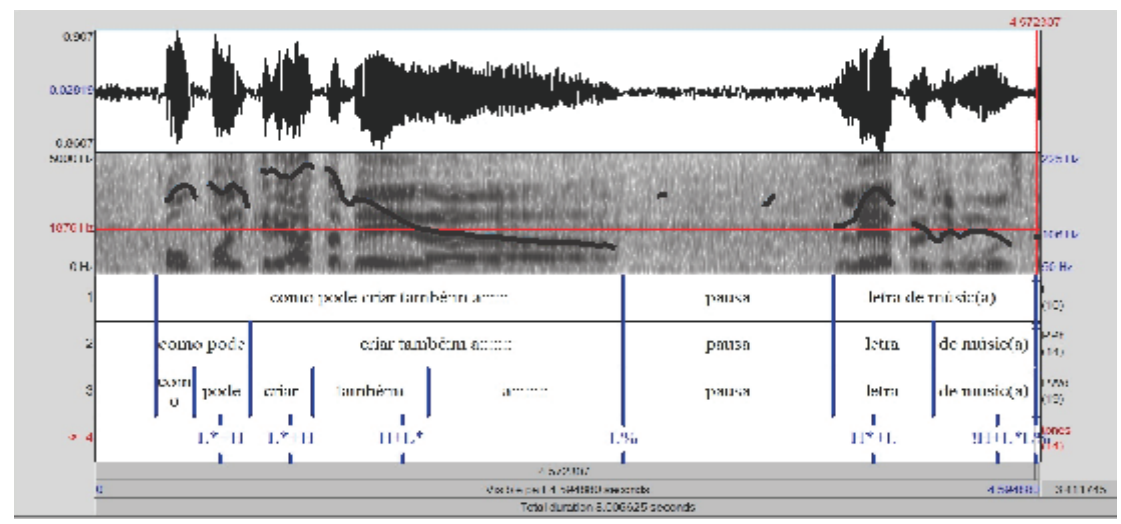

Figura 03. Forma de onda, espectrograma, contorno de $\mathrm{F}_{0}$ e camadas de fraseamento prosódico e transcrição tonal do trecho "como pode criar também a... letra de música", produzido por CBH.

Finalmente, a Figura 04, a seguir.

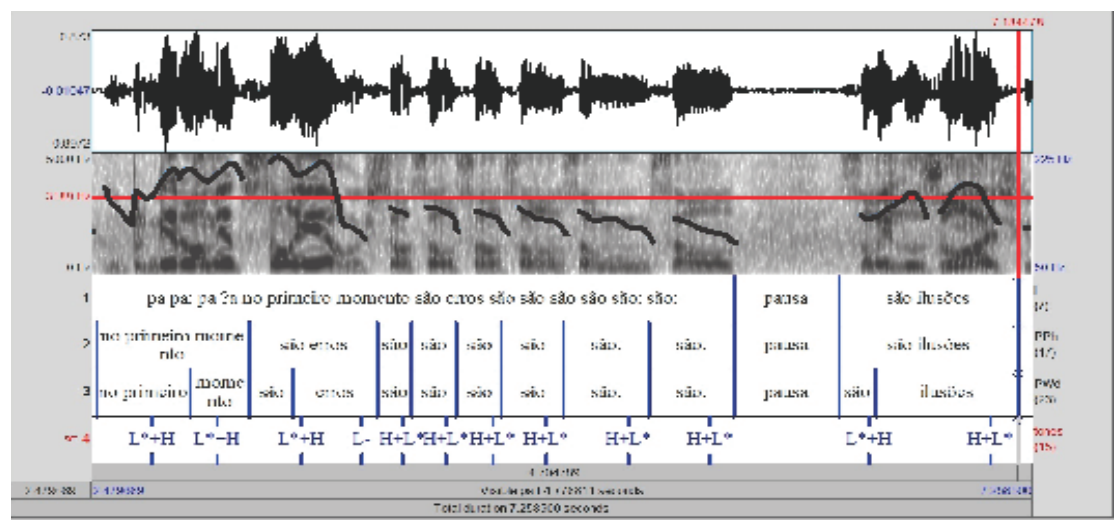

Figura 04. Forma de onda, espectrograma, contorno de $\mathrm{F}_{0}$ e camadas de fraseamento prosódico e transcrição tonal do trecho "no primeiro momento são erros são são são são são são... são ilusões", produzido por $\mathrm{CBH}$.

A Figura 04 ilustra também repetição hesitativa de palavra prosódica não cabeça de frase fonológica, no caso, da palavra prosódica "são" (são) $\omega$. Não é cabeça da frase fonológica porque, na última ocorrência dessa palavra, nota-se que o elemento mais à direita da frase fonológica, portanto, cabeça desse constituinte prosódico, é a palavra "ilusões" e não "são": [(são) $\omega$ (ilusões) $\omega] \phi$. Cabe notar ainda o abaixamento de tessitura do contorno entoacional associado ao trecho de repetições hesitativas e que, em todas as repetições da palavra prosódica "são", houve atribuição de um acento tonal ( $\mathrm{L}^{*}+\mathrm{H}$ ou $\left.\mathrm{H}+\mathrm{L}^{*}\right)$. 


\section{CONCLUSÕES}

É possível concluir, através da análise geral dos dados, que as hesitações não ocorrem aleatoriamente do ponto de vista prosódico, uma vez que sua ocorrência respeita o padrão geral de comportamento prosódico do português brasileiro.

1. Não ocorrem marcas de hesitação em cabeça de frase fonológica por motivos de preservação do local de incidência do acento frasal - cf. Abaurre, 1996; Abaurre, Galves \& Scarpa, 1999; Tenani, 2002, para afirmações semelhantes sobre a preservação do local de culminância do acento frasal e bloqueio de sândi externo em PB.

2. A atribuição de acentos tonais em trechos hesitativos respeita critérios gerais de atribuição de acento tonal do português brasileiro: acentos tonais podem ser atribuídos a palavras prosódicas (cf. Fernandes, 2007a, b e Tenani \& FernandesSvartman, 2008 sobre a atribuição de acento tonal a palavras prosódicas em sentenças neutras do português brasileiro), mas não a clíticos prosódicos.

3. A configuração tonal de foco, seguindo o trecho hesitativo, é a mesma já descrita para dados de focalização do português brasileiro em sentenças sem hesitação $\left(\mathrm{H}^{*+}+\mathrm{L}\right.$ ou L*+H L-, cf. Fernandes, 2007 a e b).

Assim, a hipótese avançada em Scarpa (1995; 2006) comprova-se: a disfluência espalha-se pelo enunciado (Merlo, 2012 e neste volume), mas tende a aparecer mais no início dos domínios prosódicos (frase fonológica ou frase entoacional, segundo o que encontramos nos nossos dados) do que nas sílabas do fim das unidades rítmicas e entoacionais. Estas, em português brasileiro, correspondem às sílabas átonas à direita da última sílaba tônica, cabeça de frase entoacional. Tal hipótese fica mais bem embasada neste trabalho, com o instrumental de Fonologia Prosódica e Entoacional: as incidências das repetições e alongamentos hesitativos obedecem a certas especificações previstas pela Teoria, que, por sua vez, podem mostrar-se relevantes para a análise de fala espontânea.

Se, como afirmado em Scarpa (1995;2006), seguindo Pêcheux (1981), que as disfluências mostram pontos de deriva, segundo a afirmação de que todo enunciado é linguisticamente descritível como uma série (lexico-sintaticamente determinada) de pontos de deriva possíveis, tornando-se outro e abrindo-se a novas interpretações, é mister dizer também que as ocorrências de hesitação não são aleatórias do ponto de vista prosódico.

As conclusões a que chegamos aqui seriam melhor vistas como hipóteses para pesquisas posteriores, a serem submetidas ao escrutínio de uma maior base de dados e de outros estilos de fala: a leitura e a fala semi-espontânea, por exemplo.

\section{REFERÊNCIAS BIBLIOGRÁFICAS}

ABAURRE, M. B. M. (1996). Acento frasal e processos fonológicos segmentais. Letras de Hoje, v. 31, n. 2, p. 41-50.

ABAURRE, M. B.; GALVES, C.; SCARPA, E. M. (1999). A Interface Fonologia-Sintaxe. Evidências do Português Brasileiro Para Uma Hipótese Top-Down de Aquisição da Linguagem. In: SCARPA, E. M. (Org.). Estudos de prosódia. Campinas: Editora da UNICAMP. 
BECKMAN, M. \& PIERREHUMBERT, J. (1986). Intonational Structure in Japanese and English. Phonology Yearbook, n. 3, p. 255-310.

BOERSMA, P. \& WEENINK, D. (2009). Praat: doing phonetics by computer (Version 5.1.15) [Computer Program]. Retrieved August 30, 2009, from: http//: www.praat.org/.

CRUTTENDEN, A. (1997). Intonation. Cambridge: Cambridge University Press, 2a. edição.

CRUZ, M. (2009). Gaguez. Em busca de um padrão prosódico e entoacional. Dissertação de mestrado, Universidade de Lisboa.

FERNANDES, F. R. (2007a). Tonal association in neutral and subject-narrow-focus sentences of Brazilian Portuguese: a comparison with European Portuguese. Journal of Portuguese Linguistics, v. 5/6, p. 91-115.

. (2007b). Ordem, focalização e preenchimento em português: sintaxe e prosódia. Tese (Doutorado em Linguística) - Universidade Estadual de Campinas, Campinas.

FINN, P \& INGHAM, R. (1991). The selection of "fluent" samples in research on stuttering: conceptual and methodological considerations. In Healey, Ch (org.). Readings on research in stuttering. Nova Iorque: Longman Publishing Group, p. 91-109.

FROTA, S. (2000). Prosody and focus in European Portuguese. Phonological phrasing and intonation. New York: Garland Publishing.

FROTA, S. \& VIGÁRIO, M. (2000). Aspectos de prosódia comparada: ritmo e entoação no PE e no PB. In: CASTRO, R. V. \& BARBOSA, P. (Orgs.) Actas do XV Encontro Nacional da Associação Portuguesa de Linguística. Coimbra: APL, v.1, p. 533-555.

HAYES, B. \& LAHIRI, A. (1991). Bengali intonational phonology. Natural Language \& Linguistic Theory, v. 9, n. 1, p. 47-96.

JUN, S-A. (2005). Prosodic Typology - The Phonology of Intonation and Phrasing. New York: Oxford University Press.

KOCH, I. G. V. ; SILVA, M. C. P. S. (1996). Atividades de Composição do Texto Falado: A Elocução Formal. In M. Basílio. (Org.). Gramática do Português Falado IV. Estudos Descritivos. Campinas, Editora da UNICAMP, p. 379-410.

LADD, D. R. (1996). Intonational Phonology. Cambridge: CUP. (2008). Intonational Phonology, 2nd edition. Cambridge: CUP.

LINDBLOM, B. (1990). Phonetic variation and selection. PERILUS XI, p. 65-100.

MARCUSCHI, L. C. (1999). A hesitação. In: NEVES, M. H. de M. (Org.). Gramática do português falado, VII: Novos estudos. Campinas, SP: Editora Unicamp.

MERLO, S. (2006). Hesitações na fala semi-espontânea: análise por séries temporais. Dissertação (Mestrado em Linguística). Instituto de Estudos da Linguagem, Universidade Estadual de Campinas.

. (2012). Dinâmica temporal de pausas e hesitações na fala semi-espontânea. Tese (Doutorado em Linguística). Instituto de Estudos da Linguagem, Universidade Estadual de Campinas.

NESPOR, M. \& VOGEL, I. (1986). Prosodic Phonology. Dordrecht: Foris Publications.

PIERREHUMBERT, J. (1980). The phonology and phonetics of English intonation. Tese (Doutorado em Linguística) - M.I.T., Cambridge, Mass.. 
SCARPA e FERNANDES-SVARTSMAN - A estrutura prosódica...

PIERREHUMBERT, J. \& BECKMAN, M. (1988). Japanese Tone Structure. Cambridge, Mass.: M. I. T. Press.

SCARPA, E. M. (2006). (Ainda) sobre o sujeito fluente. In Lier-de-Vitto, M.F. (org.). Sobre a Aquisição, Patologias e Clínica de Linguagem. Sâo Paulo, Editora da PUC-SP. p. 161-180. . (1995). Sobre o sujeito fluente. Cadernos de Estudos Lingüísticos, 29, Campinas, p. 163-184. . (1987). Aquisicao da Linguagem e Aquisicao da Escrita: Continuidade Ou Ruptura?. Estudos Lingüisticos v. XIV, p. 118-129.

SCLIAR-CABRAL, L.; MARTIM, E. \& CHIARI, B. (1981). Fenômenos de pausa e hesitação em língua portuguesa. Anais do IV Encontro Nacional de Linguística, PUC- RJ, setembro de 1981.

SELKIRK, E. O. (2000). The interaction of constraints on prosodic phrasing. In: HoRNE, M. (Ed.). Prosody: Theory and Experiment. Netherlands: Kluwer Academic Publishers, p. 231-261. . (1986). On derived domains in sentence phonology. Phonology Yearbook, n. 3, p. 371-405. . (1984). Phonology and Syntax: The Relation between Sound and Structure. Cambridge: The M.I.T. Press.

SERRA, C. R. (2009). Realização e percepção de fronteiras prosódicas no português do Brasil: fala espontânea e leitura. Tese (Doutorado em Linguística) - Universidade Federal do Rio de Janeiro.

TENANI, L. E. (2002). Domínios prosódicos no Português. Tese (Doutorado em Linguística). Instituto de Estudos da Linguagem, Universidade Estadual de Campinas.

TENANI, L. E. \& FERNANDES-SVARTMAN, F. R. (2008). Prosodic phrasing and intonation in neutral and subject-narrow-focus sentences of Brazilian Portuguese. In: Fourth Conference on Speech Prosody 2008, 2008, Campinas. Proceedings of Fourth Conference on Speech Prosody 2008. Campinas: RG/CNPq, p. 445-448.

TRAVAGLIA, L. C. (2006). O relevo no processamento da informação. In: JUBRAN, C. C. A. S.; KOCH, I. G. V. (orgs) Gramática do português culto falado no Brasil: construção do texto falado. Campinas: Editora da UNICAMP, p. 167-215.

VIGÁRIO, M. (1998). Aspectos da Prosódia do Português Europeu: estruturas com advérbio de exclusão e negação frásica. Braga: CEHUM.

VIGÁRIO, M. \& FERNANDES-SVARTMAN, F. R. (2010). A atribuição de acentos tonais em compostos no português do Brasil. In: BRITO, A. M.; SILVA, F.; VELOSO, J.; FIÉIS, A. (Orgs.) XXV Encontro da Associação Portuguesa de Linguística - Textos Seleccionados. Porto: Tip. Nunes, Ltda - Maia, v. 1, p. 769-786.

VISCARDI. J. (2012). Repetições hesitativas na fala afásica e não-afásica. Tese (Doutorado em Linguística). Instituto de Estudos da Linguagem, Universidade Estadual de Campinas. 